\title{
Opinions on early-age marriage and marriage customs among Kurdish-speaking women in southeast Turkey
}

\author{
Meliksah Ertem, Tahire Kocturk
}

\begin{abstract}
Objectives For women, marriage before the age of 18 years has adverse consequences for physical, mental and emotional well-being and constitutes a barrier for continued education. According to a national survey, about $50 \%$ of all women in Eastern Turkey were aged under 18 years at first marriage.
\end{abstract}

Methods This study explored women's opinions and experiences of early marriage and culture-specific marriage customs in the province of Diyarbakir, a region of Turkey populated mostly by people of Kurdish ethnicity. A random sample of 966 women aged 15 years or older living in urban and rural areas of the province completed a questionnaire on age at marriage and social status. Qualitative data on women's opinions and experiences were also collected through focus group interviews with 90 women.

Results The frequency of early marriage ranged from $19 \%$ in the youngest age group to $63 \%$ in women aged
60 years or older. Analysis of focus group interviews through a qualitative modified content method showed that girls were considered marriageable some years after the menarche and considerations regarding the protection of family honour were key factors leading parents to arrange the early marriage of their daughters, sometimes without their consent. Some culture-specific marriage customs included cradle betrothal, cousin marriage and berdel (exchange of brides between two families).

Conclusion There is a need for public health and family planning workers to create greater awareness of the adverse consequences of early marriage through parental arrangements.

Keywords arranged marriage, berdel, cousin marriage, early marriage, family honour

J Fam Plann Reprod Health Care 2008; 34(3): 147-152

(Accepted 7 June 2007)

\section{Introduction}

Despite a shift towards higher age at marriage in many parts of the world, 82 million girls in low-income countries who are now aged between 10 and 17 years will be married before their 18 th birthday, ${ }^{1}$ in violation of a number of international conventions as well as national legislation. Early marriage is often associated with early age at first delivery - often before a girl's physical growth is complete - which can have adverse health consequences for the mother and child. Pregnancy complications kill 70000 teenage girls a year. ${ }^{2}$ It also constitutes a barrier for education since girls are expected to leave school to take care of their families after marriage. This affects their intellectual development as well as their options for gainful employment and economic independence. Moreover, women who marry young may be less capable of asserting themselves and establishing their position in their husband's patriarchal household. As a result, they may have less power, status and autonomy within the household, which may affect their emotional well-being. ${ }^{3}$

Turkish civil law requires a minimum age of 18 years at marriage for both women and men and does not recognise religiously sanctioned marriage before that age. ${ }^{4}$ However, a national survey in 2003 showed that $34.7 \%$ of all women in Turkey had been married, mostly through a religious ceremony, before the age of 18 years. ${ }^{5}$ This figure is estimated to be as high as $50 \%$ in the eastern regions of the

Department of Public Health, School of Medicine, Dicle University, Diyarbakir, Turkey

Meliksah Ertem, MD, Public Health Specialist

Karolinska Institute, Center for Family Health and Community Medicine, Huddinge, Sweden

Tahire Kocturk, PhD, Dr Med Sci, Director of Centre

Correspondence to: Dr Meliksah Ertem, Department of Public Health, School of Medicine, Dicle University, 21280 Diyarbakir, Turkey. E-mail: mertem@dicle.edu.tr

\section{Key message points}

- About $50 \%$ of all women in Eastern Turkey are younger than 18 years old at first marriage.

- This study conducted in one of the provinces of the southeast region of Turkey, populated mostly by Kurdish people, shows that traditional considerations regarding the protection of family honour are key factors leading parents to arrange the early marriage of their daughters, sometimes without their consent.

- Some culture-specific marriage customs in the area include cradle betrothal, cousin marriage and berdel.

country. The region has the highest illiteracy rates, with $30 \%$ of the population not having had any schooling. Population growth rate is $2.1 \%$, also the highest in the country. ${ }^{6}$ In 2002, the mean age at marriage among girls in this region was $17.4 \pm 3.2$ years, with $16.3 \%$ of all women marrying under the age of 15 years. ${ }^{7}$ Another study has shown that a majority of marriages $(61.2 \%)$ were arranged by the girl's parents. ${ }^{8}$

Reasons for early marriage among girls in this region include their subordinate gender status perpetuated through customs such as parental arranged marriage, endogamous marriage systems (i.e. cousin marriage), the bride price and the special concept of family honour, which ascribes rigid norms of sexual conduct for women. ${ }^{8-11}$

This study aimed to explore the frequency and distribution of age at first marriage, educational status and cousin marriage and opinions and experiences of early marriage and local marriage customs among women resident in the Diyarbakir province in southeast Turkey, comprising mostly individuals of Kurdish ethnicity.

\section{Methods}

The study was carried out in Diyarbakir province during the spring of 2004. This province includes the largest city in the region, Diyarbakir, and its suburban and rural environs. 


\section{The survey}

The first part of the study involved collecting quantitative demographic information. A representative sample was drawn from the population of all women over the age of 15 years $(n=316000)$ registered at the Health Directorate of Diyarbakir. The sample size was determined according to the procedure described in the World Health Organization manual on Sample Size Determination in Health Studies, ${ }^{12}$ assuming a level of significance of $5 \%$ to the power of $90 \%$ and an anticipated participation rate of $45 \%$. The minimum sample size was found to be 837 . This figure was rounded to reach a population of 1000 . Multistage cluster sampling was used to reduce standard error and bias. A total of 50 clusters (30 from urban and 20 from rural areas) were selected according to the proportion of the rural/urban distribution of the region. Twenty women were drawn from each cluster. The interviewers received maps of the survey areas in each cluster with street and house numbers, if available. They selected house numbers using random tables, or alternatively they selected door numbers using random tables to determine which households to visit. All women were contacted by door knocking and interviewed orally, face-to-face. Potential participants were first informed about the aims of the study and asked to fill in a short, pre-tested and structured questionnaire comprising around 10 multiple-choice items. Questions included age at marriage, current age and marital status, level of education and type of marriage. There were no questions of an intimate or political nature. Before questioning began, the anonymity and confidentiality of the participants were ensured, and it was made clear that participants were free to decline to participate at any stage. Thirteen women declined and information from 21 women was discounted due to incomplete or contradictory responses. The dropout rate was therefore $0.3 \%$. The final sample for the survey comprised 966 women.

The interviews were carried out by female senior year students attending the School of Nursing at Diyarbakir University. A total of 20 interviewers speaking the local dialect of Kurdish (Kurmanch) and Turkish were employed in data collection. The interviewers worked in pairs, thus the data collection team consisted of 10 units. Prior to the study, the interviewers underwent a week of intensive training on the aims of the study, interview techniques, research ethics, random and strategic sampling methods, random tables and pre-testing of the questionnaires. During the study the interviewers worked under the supervision of researchers and the chief health officer of the health centre in the respective localities.

\section{Statistical analysis}

Statistical analyses were performed using Epi Info ${ }^{\mathrm{TM}} 2000$ (Centers for Disease Control and Prevention, Atlanta, GA, USA). The frequency distributions of early marriage according to current age, educational level, area of residence and cousin marriage were computed and differences tested for significance with the Chi-square method. Crude odds ratios (OR) and $95 \%$ CI were also calculated to evaluate the risk for early marriage at each level.

\section{Focus group discussions}

Eight focus group discussions (FGDs) were conducted in four urban and four rural areas of the province. Urban women were recruited through strategic sampling in four different city districts, through publicising the activity at local laundromats, family planning associations and health centres. Rural women were recruited with the help of government-employed midwives active in the health centres of four villages. A total of 90 women (43 urban and 47 rural) participated in the FGDs.

FGDs were conducted in Turkish or in Kurmandji by a female social anthropologist with experience in qualitative research techniques. Each session was attended by two observers who assisted with recording the discussions and taking notes. Discussions focused on reasons for early marriage, opinions on its effects on women's health, and local marriage customs. All FGDs were tape recorded with the consent of the participants. Each FGD lasted about 2 hours. Recorded material was transcribed verbatim, identified and translated into Turkish. Transcripts were analysed using a qualitative content analysis method. ${ }^{13}$ Many participants used local concepts or metaphors to express the same theme or idea. The content of the transcripts were reviewed together by the data collection team and key statements were identified and coded, linguistically modified and classified according to the corresponding theme. Expressions/statements were counted and grouped as those mentioned with the highest frequency, most common and least frequent (about $<75 \%, 25-75 \%$ and $<25 \%$, respectively). Personal experiences, if imparted, were noted separately. FGDs continued until saturation was reached. At the end of the study, content analysis results from all transcripts were pooled together and recounted and grouped under common themes.

\section{Ethical approval}

The study aim was to collect information and it thus had no experimental component that could endanger the health or safety of the participants, in compliance with the World Medical Association's Declaration of Helsinki. ${ }^{14}$ Participation was based on voluntary informed consent. Participants were orally informed about the aims of the study. Their anonymity was ensured. Voluntary participation was stressed before the interviews began. Subjects were free to decline or terminate their participation at any point in the study.

All collected data were kept confidential and were not accessible to individuals outside the research team. All data were anonymised prior to analysis. The study design, questionnaires and their ethical aspects were presented and extensively discussed at two internal academic meetings at the Department of Public Health and the study commenced having been approved by the Academic Committee of the Department in January 2004.

\section{Results}

\section{The survey}

A total of 996 women aged between 15 and 87 years participated in the survey. Table 1 presents some characteristics of the sample. The majority $(51.1 \%)$ of the respondents were in the 20-39 years age group and currently married (62.2\%). Educational status was low, with almost $60 \%$ of the women lacking any type of schooling and about $35 \%$ having only attended primary school for a few years. More than $42 \%$ of all women questioned had been married before attaining the age of 18 years. The frequency of early marriage ranged from $19.3 \%$ in the youngest age group to $63 \%$ in women aged 60 years or older. Differences according to age groups were significant and educational level was highly significant. The likelihood of having had an early marriage was more than 10 times higher among women with no education (illiterate) and decreased to an OR of 8.18 in women with fewer than 9 years of education (OR analyses are not shown in Table 1, but are available from the authors). 
Table 1 Frequency of early marriage according to current age, educational status, area of residence and endogamous marriage $(n=966)$

\begin{tabular}{|c|c|c|c|c|c|}
\hline \multirow[t]{2}{*}{ Characteristic } & \multirow{2}{*}{$\begin{array}{l}\text { Mean age } \\
\text { (years) (SD) }\end{array}$} & \multicolumn{2}{|c|}{ Study group } & \multicolumn{2}{|c|}{ Married $<18$ years } \\
\hline & & $n$ & $\%$ & $n$ & $\%$ \\
\hline Current age (years) & $33.2 \quad(5.7)$ & & & & \\
\hline$<19$ & & 83 & 8.6 & 16 & $19.3^{*}$ \\
\hline $20-39$ & & 523 & 54.1 & 188 & 35.9 \\
\hline $40-59$ & & 260 & 26.9 & 143 & $55.0^{*}$ \\
\hline $60+$ & & 100 & 10.4 & 63 & $63.0^{*}$ \\
\hline \multicolumn{6}{|l|}{ Current marital status } \\
\hline Married & $36.3(3.3)^{*}$ & 601 & 62.2 & 370 & 61.6 \\
\hline Single & $19.2(4.5)^{*}$ & 296 & 30.7 & - & - \\
\hline Widowed & $54.3(12.2)^{\star}$ & 69 & 7.1 & 40 & 58.0 \\
\hline \multicolumn{6}{|l|}{ Educational status } \\
\hline Illiterate & $42.8(16.6)^{\star \star}$ & 570 & 59.1 & 278 & $48.8^{*}$ \\
\hline Low (1-8 years) & $29.3(10.8)^{*}$ & 335 & 34.7 & 127 & $37.9^{*}$ \\
\hline High (>9 years) & $22.9(8.7)^{*}$ & 62 & 6.2 & 5 & 8.1* \\
\hline \multicolumn{6}{|l|}{ Area of residence } \\
\hline Rural & $32.0(16.1)$ & 375 & 38.8 & 164 & 43.7 \\
\hline Urban & $33.4(15.4)$ & 591 & 61.2 & 246 & 41.6 \\
\hline \multicolumn{6}{|l|}{ Cousin marriage } \\
\hline Yes & $40.2(15.3)^{*}$ & 394 & 40.8 & 186 & 47.2 \\
\hline No & $37.5(17.4)$ & 572 & 59.2 & 224 & $39.1^{*}$ \\
\hline Totals & & 966 & & 410 & 42.4 \\
\hline
\end{tabular}

${ }^{*} p<0.05,{ }^{* *} p<0.01 . \mathrm{SD}$, standard deviation.

\section{Focus group discussions}

\section{Opinions on early marriage}

Table 2 shows a summary of the opinions that emerged from the content analysis of the FGDs. There was agreement that marriage before the age of 15 years was too early. Girls were considered marriageable some years after the menarche, at a time between their 15th birthday and their early 20s. The major reason for early marriage was protection of family honour. Participants voiced the widely-held conviction that the sooner a girl got married, the less opportunity she would have for illicit romantic love affairs, a situation that would stain her and her family's reputation. The verbatim translation of the statement "the longer time water stays in the lake, the filthier it gets" is an expression of the belief that unmarried women are perceived as a potential threat to family honour. Older women also mentioned the desirability of early marriage, often by using a popular aphorism basgöz etmek, which loosely translated means "to give a head and an eye (to a girl)". The saying refers to the belief that a woman, if unmarried, does not have a proper head (to think with) or a proper eye (to see things in the correct perspective) and therefore is vulnerable to making mistakes and staining her reputation. Apart from honour-related reasons, women also mentioned utilitarian reasons for early marriage such as the convenience, for men, of "bringing in a girl" to take care of his older parents or perform other household chores. That young girls are more flexible than adult women and more easily acclimatise to conditions in a new household was also such a utilitarian explanation. The male preference for youthful brides was also mentioned as a reason for early marriage.

Table 2 Summarised content analysis of focus group discussions for women's opinions on early marriage (original expressions have been modified)

\begin{tabular}{|c|c|c|c|}
\hline \multirow[t]{2}{*}{ Topic } & \multicolumn{3}{|l|}{ Opinion expressed } \\
\hline & Most frequent (>75\%) & Common (25-75\%) & Less frequent $(<25 \%)$ \\
\hline $\begin{array}{l}\text { When is an early age at } \\
\text { marriage for girls? }\end{array}$ & \multicolumn{3}{|l|}{ Before 15 years. } \\
\hline $\begin{array}{l}\text { When should a girl get } \\
\text { married? }\end{array}$ & Between 14 and 17 years. & $\begin{array}{l}\text { When she reaches puberty or menarche } \\
\text { or develops breasts. }\end{array}$ & Before she reaches 20 years. \\
\hline \multirow[t]{3}{*}{ Why do girls marry early? } & $\begin{array}{l}\text { Unmarried girls get ideas and } \\
\text { admirers with increasing age. }\end{array}$ & Because girls need "a head and an eye". & $\begin{array}{l}\text { Because they are beautiful or } \\
\text { talented. }\end{array}$ \\
\hline & \multirow{2}{*}{$\begin{array}{l}\text { This may damage a girl's } \\
\text { reputation and her family } \\
\text { honour. }\end{array}$} & Because men prefer young girls. & \multirow{2}{*}{$\begin{array}{l}\text { A man may need a young girl to } \\
\text { take care of him or his parents. }\end{array}$} \\
\hline & & $\begin{array}{l}\text { "The longer time water stays in the lake, } \\
\text { the filthier it gets." }\end{array}$ & \\
\hline $\begin{array}{l}\text { What is positive about } \\
\text { early marriage? }\end{array}$ & $\begin{array}{l}\text { A young bride adapts more } \\
\text { easily to her new family. }\end{array}$ & $\begin{array}{l}\text { If she does not marry she may fall in love } \\
\text { with a stranger and elope, damaging her } \\
\text { family honour. }\end{array}$ & $\begin{array}{l}\text { A girl should marry before she gets } \\
\text { too many ideas and becomes too } \\
\text { shrewd. }\end{array}$ \\
\hline \multirow[t]{3}{*}{$\begin{array}{l}\text { What is negative about } \\
\text { early marriage? }\end{array}$} & \multirow[t]{3}{*}{$\begin{array}{l}\text { Girls find themselves married } \\
\text { before they know anything } \\
\text { about life. }\end{array}$} & $\begin{array}{l}\text { Early marriage causes problems with the } \\
\text { in-laws. }\end{array}$ & $\begin{array}{l}\text { Girls get mental, physical and sex } \\
\text { problems. }\end{array}$ \\
\hline & & Ignorant families arrange early marriages. & \multirow{2}{*}{$\begin{array}{l}\text { Early married girls get a lot of } \\
\text { babies. }\end{array}$} \\
\hline & & $\begin{array}{l}\text { Soon after marriage young girls become } \\
\text { pregnant whilst still a child themselves. }\end{array}$ & \\
\hline
\end{tabular}


Table 3 Summarised content analysis of focus group discussions for women's opinions on local marriage customs (original expressions have been modified)

\begin{tabular}{|c|c|c|c|}
\hline \multirow[t]{2}{*}{ Topic } & \multicolumn{3}{|l|}{ Opinion expressed } \\
\hline & Most frequent (>75\%) & Common (25-75\%) & Less frequent (<25\%) \\
\hline $\begin{array}{l}\text { Arranged marriage } \\
\text { (Parents arrange } \\
\text { marriages) }\end{array}$ & $\begin{array}{l}\text { In this region marriage } \\
\text { decisions are made by the } \\
\text { parents or the family. }\end{array}$ & $\begin{array}{l}\text { Parents do not have to inform a girl or ask } \\
\text { for her opinion. }\end{array}$ & $\begin{array}{l}\text { Nowadays girls decide, because } \\
\text { modern girls are more intelligent. }\end{array}$ \\
\hline $\begin{array}{l}\text { Cradle betrothal } \\
\text { (besik kertme) } \\
\text { (A girl and a boy are } \\
\text { promised to each other } \\
\text { from birth) }\end{array}$ & This is very rare nowadays. & $\begin{array}{l}\text { This is good because families know each } \\
\text { other and the bride is well received by her } \\
\text { in-laws. }\end{array}$ & \\
\hline $\begin{array}{l}\text { Berdel } \\
\text { (Two families exchange } \\
\text { brides instead of paying } \\
\text { bride price) }\end{array}$ & $\begin{array}{l}\text { Berdel is an option for poor } \\
\text { people. }\end{array}$ & & $\begin{array}{l}\text { Berdel is a reason for early } \\
\text { marriage. }\end{array}$ \\
\hline Romantic marriage & & $\begin{array}{l}\text { If a girl falls in love and elopes with a boy } \\
\text { against the wishes of her parents, this will } \\
\text { damage her family honour. }\end{array}$ & $\begin{array}{l}\text { Nowadays girls refuse marriage } \\
\text { before meeting their suitors. They } \\
\text { want to make their own decisions. } \\
\text { It is necessary to be in love. } \\
\text { Marriage is impossible if there is no } \\
\text { love. } \\
\text { Youngsters should meet and get } \\
\text { acquainted before getting married. }\end{array}$ \\
\hline
\end{tabular}

The respondents mentioned reproductive health problems, birth complications and intimidating in-laws as the major negative aspects of early marriage. That early marriage interrupts further education in girls was also mentioned. One mother gave the following account.

"I married early and had no opportunity for getting educated. But I now have two daughters in high school. I want them to complete their education. But only I know what kind of troubles I'm going through. The neighbours gossip... Someone said they saw my daughter with a boy and my husband was enraged and he attacked me, saying it's my fault because I let them mingle with boys at school. I have to struggle with my husband in order to keep them in school. But I am determined. My daughters are going to complete their education."

\section{Opinions regarding marriage customs}

Table 3 presents a summary of the opinions that emerged from the FGDs regarding certain marriage customs. The marriages of most of the respondents had been arranged. Many women mentioned the decisive role that parents play in arranging marriages.

"My father gave me away when I was 21 ... I met my husband first at our wedding."

"My parents did not inform me, or ask if I wished to get married."

"My father gave me away as a berdel-bride. I first met my husband after the wedding."
Respondents were somewhat ambivalent about the authority parents exercised without seeking their consent, but were hesitant about being too critical.

The customs of cradle betrothal (a type of infant marriage whereby a girl is promised to marry a certain boy at birth) and berdel (exchange of brides between two families) were considered to be rare events, but nevertheless a few of the study participants had experienced them.

"One girl I know had a cradle betrothal. Why wait long, when you already are promised? She married early, so she could get used to the ways of her promised family."

"My brother brought a bride from strangers (i.e. not relatives) and in return for that bride my father gave me away to my husband's family."

There was a high degree of awareness of the economic considerations behind arranged marriage, particularly berdel and cousin marriage. In berdel, grooms circumvent paying a bride price by exchanging women, instead of cash, between households. Thus berdel was seen as an option for marriage for the poor.

Cousin marriage, on the other hand, was a common experience for many respondents.

"I got a suitor and my father approved of him without consulting with my uncle whether his son wanted me. My uncle was enraged at my marriage and still will not talk with my father."

"They had good economy and in order to keep the money within the family they let the children get married when 
they were 12. The children couldn't be man and wife for several years."

Cousin marriages were mentioned primarily as being economical for the larger family. Keeping a girl within the family preserves her productive and reproductive capacity as well as the bride price within the extended family economy. Opinions expressed about cousin marriage were generally positive, also because it ensured better adjustment, reception and protection for a bride in the household of relatives. No opinions on negative health aspects of cousin marriage were mentioned.

Romantic marriage, in general, was considered a rare occurrence and a somewhat modern innovation.

"I got married because I was very beautiful and I fell in love with my husband."

"A girl need not wait for a suitor if beauty and love are involved."

"I have two daughters aged 24 and 26. They do not want to get married unless they fall in love."

Romantic marriage was also considered an occurrence that may require elopement.

"I had been promised to my paternal uncle's son. I did not want this marriage. When they insisted, I eloped with my present husband to avoid my paternal cousin."

\section{Discussion}

The results of this study confirm the subordinate position and the very low level of education among women in the Diyarbakir province and provide a number of clues about customs and opinions that influence early marriage decisions. Even though there was agreement that marriage before the age of 15 years is too early and should be avoided, a more suitable age for marrying was proposed to lie somewhere between 15 years and the early 20 s, which still is early for young girls who, after marriage, are expected to carry the huge burdens of childbirth and care and all the other duties entrusted to brides in extended families..$^{11}$ The finding is in agreement with Ilkkaracan ${ }^{8}$ who found that $97 \%$ of all women in the region are married by the time they attain the age of 24 years.

This study also confirms that, in this region, the majority of marriage decisions were not made by the young women themselves, but by their parents, in the form of arranged marriages, including customs such as cradle betrothal, berdel and cousin marriage. Parental decisions such as marrying off daughters before the age of 18 years and without their consent are violations of Article 16 of the Universal Declaration of Human Rights, the 1989 Convention on the Rights of the Child and the 1979 Convention on the Elimination of All Forms of Discrimination Against Women, ${ }^{3}$ as well as Turkish civil law. ${ }^{4}$ Islam also prohibits marriage without consent. ${ }^{15}$ Furthermore, early marriage, before the age of 18 years, can lead to serious reproductive health problems ${ }^{2}$ and cousin marriages are known to cause complications. ${ }^{16}$

In a majority of extended families and/or tribal formations in the southeast region of Turkey, populated mostly by Kurdish-speaking people, adult male dominance over women (and children) is absolute. These patriarchal formations withhold the ideology that men are rational while women are emotional and thus unable to make appropriate decisions. The values, attitudes and rules of the patriarchal family are encompassed within the so-called honour ethic, which legitimates male control of all aspects of female autonomy and sexuality. ${ }^{9-11}$ The value of a woman before marriage depends on her virginity, and afterwards on her chastity. In arranging marriages, including cradle betrothal and berdel, the crucial decision is made by the father, supported by his wife and other relatives and considered more protective of family honour. ${ }^{17}$ Moreover, cultural values and economic considerations in the region encourage cousins to marry. In this way property and bride price are maintained within the extended family. ${ }^{17,18}$ A Turkish national study conducted in 1996 demonstrated the frequency of paying bride price to be $28 \%$. In rural areas this figure is as high as $60 \%$ and is $78 \%$ in Eastern Turkey. ${ }^{19}$ These are manifestations of the patriarchal family dominance over young women, which takes parental rights to its extreme, especially when they involve the marriage of (often young) daughters to (often much older) men they may not know, may have never seen or spoken to, and often with whom they do not want to be. It is noteworthy that the respondents in this study were hesitant to criticise this type of parental dominance in marriage decisions. Another important finding was the high occurrence of cousin marriage and the lack of awareness of its medical complications for any offspring. ${ }^{16}$

When women are subordinated to the level of family property that can be exchanged for money or other services between families; when marriage at a young age, such as after menarche or between the age of 15 and 22 years is given such a priority; when preserving virginity becomes an issue of life or death; ${ }^{20}$ when being a virgin is considered a more important female trait than schooling; and when parents have the exclusive right to control their daughters' education, sexuality and choose their marital partners, it is difficult for these subjugated women to plan for a future that includes good reproductive health, education, gainful employment, economic independence and personal happiness.

These practices seem to be well ingrained in the traditions of this region. It is important that governments as well as non-governmental and human rights organisations make concerted efforts to increase the educational level of women and men and provide them with the means to gain economic independence outside the realm of their families or tribes.

There is also a great need for public health and family planning organisations to create greater awareness of the adverse consequences of early marriage through parental arrangements, for the physical, mental and emotional wellbeing of young women.

\section{Strengths and limitations of the study}

To the best of the authors' knowledge, this is the first study to focus on the opinions of women on early marriage and marriage customs in the southeast region of Turkey, using data collected directly from women participants expressing themselves in their own language. This is the greatest strength of this study. That some views and opinions may have been overlooked or misinterpreted in the process of translating the discussions from Kurmandji to Turkish might have posed a limitation on the study. The demographic information in this study is representative of women living in the province of Diyarbakir. The results may not, however, be generalised to other regions of Turkey, which is a large country, other than to populations that speak the Kurmandji dialect.

\section{Acknowledgements}

The authors are grateful to the Academic Committee of the Department of Public Health of Diyarbakir University for their permission, financial and moral support in respect of this study. They also wish to thank the School of Nursing, the personnel working at the Center for Women's Questions at the Diyarbakir Municipal Department, and Ms Zuhre Karacomak and Özge Abaci Bozyel for their assistance at the various stages of data collection. 
Statements on funding and competing interests

Funding None identified.

Competing interests None identified.

\section{References}

1 United Nations Children's Fund (UNICEF). Early Marriages: Child Spouses (Innocenti Digest, No. 7). Florence, Italy: UNICEF Innocenti Research Centre, 2001. http://www.uniceficdc.org/publications/pdf/digest7e.pdf [Accessed 3 January 2006].

2 Ahmad K. Pregnancy complications kill 70000 teenagers a year. Lancet 2004; 363: 1616.

3 Jensen R, Thornton R. Early female marriage in the developing world. Gend Dev 2003; 11: 9-19.

4 Turk Medeni Kanunu Madde 124 [The Turkish Civil Law, paragraph 124 - in Turkish]. Resmi Gazete 2002; 12 August.

5 Ergocmen BA, Eryurt MA. Other determinants of fertility. In: The Turkish National Health Survey - 2003. Hacettepe Institute of Population Research. Ankara, Turkey: Hacettepe University Press, 2003; 92.

6 State Institute of Statistics, Republic of Turkey. Turkish Census of Population 2000. Social and Economic Characteristics of the Population, Province of Diyarbakir. Ankara, Turkey: Office of the Prime Minister, 2002.

7 Saka G. Güneydoğu Anadolu Bölgesinde Kadınların Durumu [The status of women in Southeast Turkey - in Turkish]. In: Ulusal Halk Sağliğı Kongresi Kitabı [Proceedings of the National Public Health Congress, 2002]. Diyarbakir, Turkey: University of Diyarbakir, 2002; 41.

8 Ilkkaracan P. Exploring the context of women's sexuality in Eastern Turkey. In: Ilkkaracan P (ed.), Women and Sexuality in Muslim Societies. Istanbul, Turkey: Women for Women's Human Rights, New Ways, 2000; 66-75.

9 Sev'er A, Yurdakul G. Culture of honor, culture of change: a feminist analysis of honor killings in rural Turkey. Journal Title 2001; 7: 964-998.

10 Kagitcibasi C. Status of women in Turkey: cross-cultural perspectives. Int J Middle East Stud 1992; 18: 485-499.

11 Kocturk T. Family formations and lifestyles. In: A Matter of
Honour: Experiences of Turkish Women Immigrants. London, UK: Zed Press, 1992; 63-82.

12 Lwanga SK, Lemeshow S. Sample Size Determination in Health Studies: A Practical Manual. Geneva, Switzerland: World Health Organization, 1991; 29.

13 Green J. Thematic content analysis. In: Qualitative Methods for Health Research. London, UK: Sage Publications, 2004; 177-179.

14 Post SG (ed.). Encyclopedia of Bioethics (3rd edn). New York, NY: Macmillan Reference, 2004; Vol. 5, 2819-2821.

15 Kordvani $\mathrm{AH}$. Hegemonic masculinity, domination and violence against women. Paper presented at the Conference on "Expanding Our Horizons: Understanding the Complexities of Violence Against Women", Sydney, Australia, 18-22 February 2002. http://66.249.93.104/search?q=cache:hWVeLWhkifoJ: www.austdvclearinghouse.unsw.edu.au/Conference\%2520pap ers/Exp-horiz/Kordvani.pdf [Accessed 3 January 2006].

16 Bennett RL, Motulsky AG, Bittles A, Hudgins L, Uhrich S, Doyle $\mathrm{DL}$, et al. Genetic counseling and screening of consanguineous couples and their offspring: recommendations of the National Society of Genetic Counselors. J Genet Counsel 2002; 11: 97-119.

17 Carroll L. Arranged marriages: law, custom and the Muslim girl in the UK. In: Ilkkaracan $\mathrm{P}$ (ed.), Women and Sexuality in Muslim Societies. Istanbul, Turkey: Women for Women's Human Rights, New Ways, 2000; 229-242.

18 Tezcan M. Beşik Kertme Nişanlı Geleneği ve Çayırbağı Köyü Uygulaması [The tradition of cradle betrothal and observations in Cayirbagi Village - in Turkish]. Paper presented at the Second International Congress on Turkish Folklore. Ankara, Turkey: Ministry of Tourism, 1982; Vol. 4, 123.

19 GAP bölgesinde kirsal alanda kadinin toplumsal konumu [Women's status in the GAP region - in Turkish]. http://www.gap.gov.tr/Turkish/Dergi/D471996/kadin.html [Accessed 6 February 2006].

20 Sev'er A. In the Name of Fathers: Honour Killings and Some Examples from South-Eastern Turkey. http://www.utsc. utoronto.ca/ socsci/sever/pubs/name of fathers.pdf [Accessed 4 August 2006].

\section{BOOK REVIEWS}

Managing Erectile Dysfunction. M Cummings. St Albans, UK: Altman Publishing, 2006. ISBN: 1-86036-032-7. Price: £9.95. Pages: 78 (paperback)

This little gem (78 pages) is a valuable asset to health care professionals in primary care (general practitioners, nurses and psychosexual therapists). It should help health care professionals to openly discuss erectile dysfunction (ED) with clients they treat in everyday practice and to feel at ease when discussing the problem and its impact on their quality of life. It outlines the benefits of treating ED in primary care and links these with commonly associated medical conditions that contribute to it (e.g. cardiovascular disease and diabetes). Having the knowledge of various treatment options at hand will enable health care professionals to help clients access the best treatment for their individual needs.

The chapters are laid out as common questions posed by health care professionals and the answers have enough detail without being too academic. The algorithm in Chapter 6 is very helpful in this respect. The chapter on drug therapy is sufficiently detailed to allow a discussion with clients and initiation of therapy. There is a chapter devoted to alternatives to drug therapy and various methods are briefly discussed here. Use of intra-urethral and intracorporeal injection will need referral to experienced therapists who can give their time to adequately explain the procedure to the client. I especially liked the use of boxes at the end of chapters summarising key points. This book is easy to read through as well as to dip in and out of. I would have preferred colour instead of grey for the text boxes within the chapters and after each chapter as it would have made it more attractive to pick up and read as well as being easier on the eyes.

Reviewed by Neelima Deshpande, MRCOG, Dip PST

Staff Grade Doctor in Family Planning and Psychosexual Therapist, Heart of Birmingham Teaching Primary Care Trust (HoBtPCT),

Birmingham, $U K$

Women's Health: A Practical Guide for Healthcare Professionals. S Bekaert. Oxford, UK: Radcliffe Publishing, 2007. ISBN-13: $978-$ 1-84619-029-2. Price: £21.95. Pages: 208 (paperback)

I accepted this book with interest, hoping to find that it would support and inform my practice as nurse in family planning and well-women services, where many women attend with gynaecological or reproductive health problems.

The title states that it is a text for health care professionals. The introduction states that lay people may find it useful, written - as it is - using the vernacular. My heart started to sink. It dropped further when reading an explanation of 'plasma' as the fluid part of the blood. What kind of health care professionals are we talking about?

It is written in the 'symptom sorter' format, an approach with which I am unfamiliar. The book is structured around symptoms, conditions, tests and procedures. There are chapters on contraception and sexually transmitted infections at the end.
The symptom sorter section is useful. Using headings such as 'menstrual symptoms' and 'breast symptoms', presenting symptoms are described and differential diagnoses suggested (common, occasional and rare). Specific considerations in history taking, however, are listed but not explained; so much that might be useful is not covered. The author suggests that after arriving at a working diagnosis the reader should turn to the tests section before reading more about the conditions, which information is supported by 'reputable resources'.

While the symptom sorter is an interesting way of presenting the material, there is a real inconsistency in the amount of detail and analysis in the book. For example, under the symptom of vaginal dryness, a (rare) cause is Sjögren's syndrome. An explanation of this condition is not included in the 'conditions' section. However, other conditions, such as Bornholm disease and Kleinfelter's syndrome, are. It is hard to fathom where they fit in the scheme of women's health.

The resources are, with few exceptions, websites and there is no referencing as such in the book. The section on contraception at the back cites as references two websites illustrating male and female condom use. The FFPRHC (now the FSRH) is included as a "useful resource".

This text does not know who its audience is, and consequently I would find it hard to recommend it to anyone.

Reviewed by Clodagh Ross, BSc, RGN Lecturer/Practitioner in Sexual Health, Edinburgh, UK 